\title{
The Social-Psychological Implications of a Coaching Change at the Collegiate Level: Perceptions of Athletes
}

\author{
Todd A. Gilson \\ Northern Illinois University \\ Amanda L. Paule-Koba \\ Bowling Green State University \\ Emily Ann Heller \\ Northern Illinois University
}

\begin{abstract}
The purpose of this study was to better understand the social-psychological processes and outcomes athletes experience during a head coaching change. The authors conducted semistructured interviews with 47 NCAA Division I athletes, representing 11 different sports at 20 distinct institutions. Following inductive analysis of transcribed interviews, seven higher order themes emerged: emotions, academics, goals, leadership, negative effects, positive effects, and changing culture and structure of the team. According to the perceptions of athletes, results showed that coaches stressed the importance of academics and used goal setting principles with their new team. However, athletes also spoke to deficiencies in leadership and the emotional instability that resulted in a loss of confidence, increased stress, and feeling ignored by the new staff. Thus, open and honest lines of communication need to be formed early with athletes - by multiple athletic personnel-so that individuals have the support system necessary to prevent maladaptive results.
\end{abstract}

Keywords: coach, NCAA, qualitative

Sport coaches are integral to the success and experiences of athletes (Becker, 2012). For instance, guiding teams to successful outcomes is vital, as effective coaches are generally known to be individuals who positively influence athletes' behavior, performance, and produce winning teams (Horn, 2008). However, the relationships athletes develop while under the tutelage of a coach are also important because it is argued that the coach plays a central role in influencing the "moral

Gilson and Heller are with the Department of Kinesiology and Physical Education, Northern Illinois University, DeKalb, IL. Paule-Koba is with the School of Human Movement, Sport, \& Leisure Studies, Bowling Green State University, Bowling Green, OH. 
terrain" within sport experiences. Specifically, various environments, including the practice field, the locker room, and competition itself help to shape and reveal moral dimensions and character traits of athletes through their interactions with the coach (Hardman, Jones, \& Jones, 2010). Coaches too, have elaborated upon the importance of building relationships with athletes by citing the need to know athletes on a personal level. They invest time with each individual, tailor strategies to each individual athlete, and provide each individual with support throughout practices and competition (Giacobbi, Whitney, Roper, \& Butryn, 2002; Vallée \& Bloom, 2005).

Because of the breadth of influence a coach can have on an athlete, a multitude of studies have examined the coach-athlete relationship since the classic observational work of John Wooden conducted by Tharp and Gallimore (1976). For example, recent studies have examined this relationship from the perspective of the coach (Bucci, Bloom, Loughead, \& Caron, 2012; Chan, Lonsdale, \& Fung, 2012; Kamphoff, Armentrout, \& Driska, 2010; Kristiansen, Tomten, Hanstad, \& Roberts, 2012), as well as from that of the participant (Becker, 2012; Clement \& Shannon, 2011; Gyllensten, Palmer, Nilsson, Regnér, \& Frodi, 2010; Judge et al., 2012; Rhind, Jowett, \& Yang, 2012) in a multitude of settings and exploring various constructs. Furthermore, a review of the literature reveals the extensive latitude contemporary coaching studies embody, as works have examined coaches related to the Big Five personality traits within coach-athlete dyads (Jackson, Dimmock, Gucciardi, \& Grove, 2011), the perceptions of Canadian curling coaches who underwent psychological skills training programs (Paquette \& Sullivan, 2012), the important role of wheelchair rugby coaches when an athlete suffers a severe spinal cord injury (Tawse, Bloom, Sabiston, \& Reid, 2012), and coaches' attitudes and perceptions of leading transgender athletes following transition (Grajfoner, 2009).

Even with the vast array of coaching studies one important area of inquiry remains largely absent: the implications for athletes when a coach suddenly leaves a program. As we demonstrate in the following space, it is likely that athletes will experience coaching changes during their collegiate playing careers, and these transitions can negatively affect their athletic performance and overall well-being. As such, the purpose of our study was to examine the experiences of students who experienced a coaching change, and the impact of this change on their subsequent playing and academic outcomes.

\section{Conceptual Framework}

At the collegiate level, the National Collegiate Athletic Association (NCAA) does not keep statistics regarding the turnover rate of coaches each year; however, a quick examination of sport websites reveals that head coaching changes occur with regularity. For instance, in the NCAA Football Bowl Subdivision, which in 2012 consisted of 124 teams, a total of 27 head coaches left their respected institutions, for a turnover rate of 21.8\% ("2012-13 FBS head coaching changes," 2012). Furthermore, this trend is not strictly limited to college football, as during the same time period, NCAA Division I women's basketball experienced 76 head coaching changes within the 345 participating athletic programs-a turnover rate of 22\% ("List of current NCAA Division I women's basketball coaches," n.d.). Thus, with many collegiate athletes participating in their sport for a total of five 
years (including a redshirt year as a freshman), this statistic highlights that an athlete is likely to experience ending a relationship with one coach and beginning a new one with a future coach.

A period of coaching transition at the collegiate level occurs at a critical juncture during the life of a student-athlete. Collegiate athletes already experience a coaching change when they progress from high school to college level competition; thus, they must adjust to new roles and responsibilities, coaching leadership styles, teammates, and college life in general (MacNamara \& Collins, 2010). These changes, coupled with the possibility of another coaching change while in college, can negatively alter perceptions of team unity and satisfaction (Aghazadeh \& Kyei, 2009) and can result in measurable consequences for the upcoming season and career of an athlete (Hersch, 2012). For instance, in football, there is a negative relationship between a recent coaching change and points a team scores per game (Soebbing, \& Washington, 2011). In addition, a head coaching change may also negatively affect a college football player's draft status for the National Football League (NFL), resulting in an athlete losing millions of dollars over a career (Hersch, 2012). While this research does shed light on what is presently known about coaching changes from an organizational perspective, more focus is needed on the transition players experience from a social-psychological perspective, as the role and relationship a coach has with athletes can impact their training motivation and satisfaction within their sport (Goose \& Winter, 2012).

Hanin (2007) argued that while a change of coach may provide a team a brief boost, these organizational decisions generally result in difficulty on the part of the player to adapt over the long-term. This sentiment has been partially supported when investigating how athletes adapt to the different leadership styles of coaches. Specifically, through qualitative interviews, football athletes discussed the need to establish trust with a new coach and then find the strength to persevere through a new season (Pate, Stokowski, \& Hardin, 2011). Furthermore, using data from individual athletes, Sievert (2011) brought to light case studies showing the difficult decision NCAA athletes face when a coaching change occurs. Essentially, athletes must choose between honoring their past agreement with an institution to which the terms have changed or transferring after a coaching change and reengaging in the entire recruiting process again in hopes of finding greater stability, neither of which is ideal.

While there are many aspects of coach-athlete involvement worthy of study, based on the lack of research in the area of head coaching changes from the perception of the participant, the purpose of this study was to investigate the social-psychological impact on sport and academics when athletes experience a coaching change. In addition, we see value in (a) pursuing a qualitative framework to discover the "lived experiences" that these athletes underwent during this time of transition, and (b) seeking to understand the experiences of women and men, in both team and individual sports, and from a variety of institutions across the country, thereby allowing us to acquire the broadest foundational base. Utilizing these guiding principles allows us to ascertain athletes' lived experiences, social structures, and sport characteristics, which are all important factors related to performance (Carlson, 1988).

We posed the following research questions:

RQ1: What are the social processes related to a head coaching change? 
RQ2: What are the academic processes related to a head coaching change?

RQ3: What are the self-regulation processes athletes used to adjust to new demands?

\section{Method}

\section{Participants}

A total of 47 current collegiate athletes participated in this study (18 women, 29 men). At the time of participation, all athletes were members of a varsity athletic team at their respective university and had at least achieved sophomore status regarding NCAA eligibility so they could adequately speak to their experience with a coaching change. Specifically, 11 participants were sophomores, 17 were juniors, 14 were seniors, and 5 were 5 th year seniors. Finally, a total of eight unique sports were represented in the sample among participants (football $=14$; volleyball $=6$; women's soccer $=6$; baseball $=5$; men's golf $=4$; men's track and field $=3$; softball $=3$; men's soccer $=2$; women's golf $=2$; men's basketball $=1$; women's basketball $=1$ ).

\section{Instrumentation}

We conducted semistructured interviews and focused on the social-psychological impact that collegiate athletes experience when undergoing a head coaching change. Specific topics of interest included: (a) the social processes related to a head coaching change, (b) the academic processes related to a head coaching change, and (c) the self-regulation processes athletes used to adjust to new demands. A similar protocol was followed for each interview with the same set questions asked in the same order. We used probes to ascertain more information regarding a specific topic or achieve clarification regarding participants' answers (Berg, 2004; Patton, 2002).

\section{Procedure}

Once approval was granted from the Institutional Review Board a team database was developed to identify NCAA universities where a head coaching change had occurred with at least one varsity sport during the 2011-2012 academic year. This process was completed by examining a university's athletic website, and specifically, the biography of the head coach for the respective sport. Once a university and sport were identified that matched this criteria, other sports (and head coaches' biographies) at the same university were analyzed to determine if additional sports from the same university could be included in the database. The formulation of the database continued until the researchers believed they had achieved an adequate number of potential participants for data saturation, based on expected rates of participation. The complete database was comprised of 48 NCAA universities where a head coaching change was identified and a total of 74 varsity sports from these universities. The number of varsity sports from a specific university that matched the aforementioned criteria ranged from a low of one varsity sport to a high of five varsity sports.

The next step in the acquisition of participants was to populate a new database with athletes from the 74 varsity sports previously identified. Specifically, researchers gathered names and e-mails of athletes from university websites. If researchers 
could not obtain individuals' e-mail addresses from an online university directory this team was replaced with another "like" team at a different school, thus keeping intact the expected number of participants for saturation. This process yielded 799 athletes who could potentially participate in this study. To achieve the goal of obtaining a diverse and representative sample the researchers imposed two methodological strategies. First, we identified a target population of 50 participants as the likely number needed to achieve "saturation" of the data. Second, we imposed a protocol was that limited the number of participants that could be interviewed from any one team (at one university) to three. This latter principle was especially important because while qualitative research is not meant to be generalizable to a larger population because of its restrictive sample sizes (Paule \& Gilson, 2010), capping the number of participants who could speak to the same coaching change allowed the researchers to capture the most complete and diverse picture related to a collegiate coaching change.

Following these guidelines, we began systematically contacting potential participants via e-mail, no more than three at a time per identified university. During this initial e-mail the purpose of the study was conveyed to athletes, as well as the time commitment required (30-45 min). If a period of one week elapsed without a response, a second brief e-mail was sent to the athlete gauging his/her willingness to participate. Finally, if no response was received from either the first or second e-mail, we assumed that the individual was not interested in participating and the process began anew with the next athlete from the corresponding team.

If an athlete responded to either e-mail expressing a willingness to participate, the individual was e-mailed a digital copy of the consent form and asked to reply to three "yes/no" questions: (a) Was the athlete willing to participate in the study; (b) was the athlete amenable to having the interview digitally recorded; and (c) was the athlete at least 18 years old? For the interview process to continue, affirmative responses were required for the first and third questions. Upon a satisfactory response to these questions, a convenient date and time was established for the interview to take place. During the prearranged appointment, we contacted the athlete and conducted the interview, where a semistructured approach was followed. However, participants were free to elaborate upon any specific topic or question. Eventually all 799 athletes from the individual database were solicited for participation, with 103 initially agreeing to participate. However, 27 athletes stopped responding to e-mails, another nine were barred from participation by their university, and six were ruled ineligible based on responses to the aforementioned "yes/no" questions; leaving 61 athletes who were interviewed. After completion of interviews, 14 participants (and their interview data) were discarded after transcription because of a lack of substantive information resulting in a complete dataset of 47 participants in this study.

\section{Data Analysis}

We transcribed each interview verbatim. Next, the first and second authors combed through each interview and transcription to develop lower order themes using an inductive method (Patton, 2002; Silverman, 2001). After achieving consensus in the grouping of lower order themes, an identical process was used to categorize lower order themes into high order themes. 


\section{Results}

Multiple emergent themes surfaced from the interviews athletes shared as they discussed their experiences pertaining to their coaching change. Specifically, seven robust themes surfaced: emotions, academics, goals, leadership, negative effects, positive effects, and changing culture and structure of the team. Excerpts from selected interviews are used as evidence to highlight the experiences these athletes shared.

\section{Emotions}

When first hearing about their coaching change, athletes reported a wide spectrum of emotions covering the five stages of the athletic grief response, as proposed by Hardy and Crace (1990). The emotions athletes shared included: frustration / anger / upset $(n=12,26 \%)$, sadness / devastation / disappointment $(n=10,21 \%)$, shocked / surprised $(n=7,15 \%)$, happy / excitement $(n=6,13 \%)$, fear of what will come next $(n=6,13 \%)$, not surprised $(n=5,11 \%)$, empathy for the coach $(n=3,6 \%)$, confusion $(n=2,4 \%)$, and denial $(n=1,2 \%)$. The number of categorized emotions is greater than the number of participants because some individuals responded with more than one emotion. For example, a softball athlete mentioned, "At first I was kind of shocked because I thought it was out of nowhere... and then I was a little happy because I knew that our program needed a change, so sort of mixed feelings."

Other athletes took significantly longer to come to the point of acceptance regarding their coaching change. Three athletes spoke to feeling exceptionally bitter about the impending change because they originally chose their university based on their coach or they were initially recruited by the previous coach and felt a strong connection with him/her. As highlighted by Sievert (2011), it is understandable athletes would feel this way as they committed to a particular school to play for a specific coach, and when / if the coach leaves, this may lead to athletes trying to make sense of the situation and increased feelings of lack of control in their situation.

Other athletes spoke candidly to their frustration regarding the indirect method that the athletes were informed that their coach would not be returning $(n=3$, $6 \%$ - which were broadcasted on ESPN or other news sources. For example, a football athlete spoke of how he found out his coach would be leaving:

My brother actually called me and asked if coach was leaving - he had read it online. So my brother, a non-athlete for [university name] found out before me, so that was hard for me. I was upset and hurt, I was more upset that no one told the players, that we found out that way.

It is apparent that coaching change transitions can have an influence on athlete's emotions, as many athletes form close bonds with their coach. This is not surprising given the fact that the NCAA allows coaches 20 hours per week of "contact time" (NCAA, 2012), meaning the coach is the adult figure the athlete will interact with the most during the collegiate experience.

\section{Academics}

As one might expect, when asked to describe the importance of academics at their university, most athletes $(n=43,91 \%)$ categorized academics as a "top priority," 
"very important," or "academics takes precedence over their sport." Specifically, seven athletes all attending distinct universities, spoke to their belief that they are to be a student first.

Furthermore, when investigating the impact a coaching change had on athletes' academics, almost half of the athletes $(n=19,40 \%)$ mentioned that the focus on academics became more profound once the new coaching staff was hired. While on the surface it would appear that an increased focus on academics by coaches would result in similar (and positive) effects by athletes, this was not always the case. For instance, a volleyball player found the new coach emphasized academics to a greater extent than her old coach, yet the implementation of this new policy produced a negative effect. She shared:

I think it kind of hurt me a little bit just because I resisted like what [the coach] wanted me to do, just out of defiance I guess. But I think what she's doing is good in the long run, but at times, I think it's too much work. I've never done study hall and now I'm doing a lot of this extra stuff.

Although the majority of athletes $(91 \%)$ mentioned their academics are of upmost importance for themselves, not all athletes felt their coaches placed academics first. When talking about the differences between his former coach and new coach, a baseball player stated "[The coaches] were both similar pretty much, they would say all the right things you know, like [academics] were important, but we all knew baseball was the main thing and school would take a back seat." More shockingly, a football athlete highlighted how his coach spoke differently depending on the audience:

I think [our coach] prioritizes [academics]. It depends on who he's talking to. When he's talking to the athletic director or to the media about how important academics are, they're our number one priority. But then his actions behind it kind of say another story, that academics aren't that important.

Three additional athletes noted similar observations, in a sense that their coach has two different mentalities related to emphasizing academics, with the audience as the determining factor. Therefore, it is entirely possible that because of the coach's socialization, some athletes develop a greater inclination toward their sport, when weighed against academic responsibilities, supporting previous contentions highlighted Adler and Adler $(1985,1991)$.

\section{Goals}

When asked whether their new coaches incorporated strategies to help athletes reach their goals, almost half of the athletes $(n=18,38 \%)$, commented on ways their coach discussed such methods. For tangible reminders, some of those athletes $(n$ $=9,19 \%$ ) shared that their team participated in group activities to keep everyone focused on their goals. A football player discussed how there was a game board in their locker room where the team goals are clearly stated. For his team, this included beating the rival team, maintaining a team GPA above 3.0, and going undefeated for all home games. Furthermore, a baseball athlete mentioned that players are to 
record their personal goals and give them to a teammate. This way, athletes can be held accountable by their teammates.

Pertaining to the goals developed jointly by athletes and their coaches, it was interesting to note that mixtures of specific goal setting strategies were implemented. Specifically, two athletes mentioned setting exclusive process-oriented goals (e.g., how an individual should complete a task) while four discussed only outcomeoriented goals for their season (e.g., end result goals). In addition, a handful of athletes $(n=6,13 \%)$, mentioned their coach helped guide them to set a combination of outcome-oriented goals with specific focus-points to help them be more successful when working toward achieving those goals. A football athlete spoke to this:

I think just... one of the things to reach these goals, is I mean, we talked about um in our offseason training program about chunking is what we called it, is when you're presented with a big task to break it down into smaller tasks.

In addition, other athletes $(n=5,11 \%)$ mentioned their coach allocates specific segments of their team meetings or one-on-one meetings toward goal setting. In particular, a football player stated:

At the end of every school year, every spring, you kind of have a meeting with the coach where you get to list out your goals and objectives, how you wanted to accomplish them, and rate yourself on your performance. It gives you an opportunity to sit with the coach and they would give you feedback on your performance, tell you if you were stretching your goals, if they were feasible, if you weren't pushing yourself far enough.

Thus, while coaches should be commended for assisting athletes in the goal setting process, more careful attention to process-oriented goal may be warranted as these types of goals have been found to be significantly more important in terms of the long-term persistence individuals' display when striving for their goals (Burton \& Weiss, 2008).

\section{Leadership}

Perhaps the higher order theme that was surprisingly discussed most infrequently was leadership $(n=8,17 \%)$. The comments referred to how athletes took a stand to be a leader during the rough transition or how athletes felt a natural increase in the amount of responsibilities placed upon them due to the coaching change. A football player spoke to how he observed a change of leadership:

Three guys who were just as strong leaders, and that are also going into the NFL, they are just really confident. Knowing that you have them in charge of your team, as well as the administration staff - like our athletic director, it's so smooth. [The coach] knows that the biggest thing is just really strong leaders.

Obviously, having athletes with strong leadership skills is an imperative component to having a successful athletic team. In fact, Zaccaro, Rittman, and Marks (2001) contend that leadership is the most salient contributing factor when evaluating a team's overall effectiveness and successfulness. 
In contrast, other athletes acted differently in response to the transition. For example, in response to the lack of leadership an athlete on the track and field team became an emergent leader by stepping up as a team captain:

[The coaches] didn't like set me aside and say, "Okay you're gonna be team captain." It was just my leadership characteristics that I have taking over and kinda taking the initiative to lead the younger kids and they just saw that and let me do my thing. They didn't really take me aside and like give me a plan or anything.

These experiences help illustrate the importance of peer-leadership during this transitional time whether athletes arise to assume leadership roles and responsibilities within themselves or they actively seek it out from other individuals. Therefore, to aid in the satisfaction and enjoyment for all athletes, leadership may be a quality in need of cultivation before a coaching transition occurs.

\section{Negative Effects}

It comes as no surprise that athletes $(n=8,17 \%)$ experienced negative reactions to their coaching change and eight athletes spoke to this theme. These were distinct from the emotional responses and included a decrease in confidence $(n=4,9 \%)$, higher stress and pressure $(n=2,4 \%)$, new coaches ignoring older players $(n=2$, $4 \%)$, burnout from their sport $(n=1,2 \%)$, and the new coach not assisting in the transition $(n=1,2 \%)$. Some athletes spoke to multiple negative effects therefore the number of categorized responses is greater than the number of participants. Generally, this disconnect became apparent when athletes experienced difficulties adjusting to the style of the new coaching staff. Specifically, a football athlete, stated:

It was just all about telling you how awful you did and tearing you down and never really coaching you or trying to increase your confidence in your ability. So, definitely from the old staff to the new staff I lost a lot of confidence in my ability and how I play. And you could definitely see that with many players this year, just the way we performed was definitely a lot worse.

Underlying causes of athletes' negative perceptions related to their coaching change varied across participants. For example, a golfer experienced frustration because under the previous coach's leadership, when she was an underclassman but traveled to all the golf meets with the team. When the coaching staff changed, she was no longer invited to travel. A women's basketball player also felt devalued due to similar reasons and felt alienated from the team:

Being a senior [the coach] didn't really try to create any type of connection with me. I feel like she came in and it was all about her. And she didn't really care about the players on the team. She just wanted to rebuild the program with people that she's recruited and everything.

These results highlight the detrimental outcomes a coaching change can have on athletes. Whether these negative consequences result in part from athletes experiencing a second period of adjustment, similar to the transition from high school to college and not possessing the psychological skills necessary to adapt these new leadership styles (MacNamara \& Collins, 2010) or coaches failing to 
form relationships with athletes could not be answered based on the scope of this study. However, it is clear that a lack of meaningful communication should be a point of focus for both coaches and athletes alike.

\section{Positive Effects}

When examining the previous theme, one might develop the perception that all coaching changes result in unwanted turmoil for athletes. While this was the case for a select group of athletes, multiple athletes $(n=10,21 \%)$ mentioned experiencing positive changes with their new staff such as higher self-confidence ( $n=7,15 \%)$ and more motivation $(n=3,6 \%)$. For instance, a football athlete spoke about the overall increase in confidence he experienced:

I feel obviously more confident as a football player... I'm doing better in academics... overall I feel more confident as a person just because there's just been change. There's hope and it just allowed me to... experience a different thing and it does affect my confidence. It just gives a chance to turn around our program so it gives you hope.

A golfer mentioned similar experiences pertaining to her confidence levels, and the team's increase in ranking certainly added to her high spirits. Under the guidance of the team's previous coach, they were expected to finish the golf season last for their conference, but under the new coaching staff they tied in fourth place. She attributed the team's improvement to working harder as a collective unit, which was encouraged under the new coaching staff.

Furthermore, other athletes $(n=4,9 \%)$ spoke to how the new coaching staff helped improve their performance by implementing additional expectations. These included having a structured practice schedule, incorporating a consistent lifting regimen, and spending more time studying film. Though these expectations may result in additional time pressures for athletes, if coaches foster achievement strategies based on the unique attributes of the individual, it is possible to build a rapport with each athlete during the athletic season (Giacobbi et al., 2002; Vallée \& Bloom, 2005).

Therefore, with perceived changes to confidence, motivation and expectations one can see why some athletes were ecstatic about the prospect of a new changing staff. Specifically, a football player spoke about how playing for a new coach would allow him to reestablish himself as a player, and a person, with his new coach:

I just think that everything, it was a new slate. You know? As you've been around a program and you're with the head coach, you often kind of get thrown under the rug a little bit... coaches will tend to play favorites... and when you get a new coach you see an opportunity... you have a great opportunity to continue [your] dream.

\section{Changing Culture / Structure}

When introducing a new coach to an athletic team, having an awareness of program culture and structure can be important. The process a team goes through when one coach leaves and another one comes in has the potential to threaten the delicate balance between the values espoused by the previous coach and the vision of the 
new one. Consider the case of one participant (a softball athlete), who originally felt rather uncertain regarding her coaching change. Specifically, she mentioned when her coach was hired the coach habitually reinforced the team's new main focus, which was to give high effort during practice. As the athlete remarks, "Because of effort... do the same thing over and over again until you will... [achieve] that level of performance." She continued by stating that giving $100 \%$ effort should not only be applied to the softball field, but since the new coach emphasizes giving effort to a greater extent than previously advised by the former coach, she now integrates giving more effort in other areas of her life, such as academics. Although this athlete was initially unsure of the new coach, she was able to feel connected when the coach's strong reinforcement of giving effort helped her outside of athletics.

Moreover, two football athletes (4\%) shared their perception of how they view their sport culture, which they both believe is operated as a business. In particular one stated:

As students, we kind of get in a gap and adopt an idea that you know, [football] is a business. And you know, coaches are gonna do what they gotta do when there's more money on the line - or whatever it may be. [So] at the end of the day it's a business.

Viewing sports as a business has manifested itself in previous literature from Beyer and Hannah (2000) who argue that athletics generates resources for universities, which would not be otherwise available. However, it is imperative to note that this study cannot draw relationships concerning athletes' perceptions of college sports as a business or educational model. Specifically, because of limited number of participants (and the fact that nine athletes were excluded from participating by their universities) a natural bias may be evident. Therefore, these notions are shared to add breadth to the overall experience of athletes experiencing a coaching change at the collegiate level.

\section{Discussion}

The purpose of this study was to explore athletes' experiences after a head coaching change at the collegiate level from a social-psychological perspective. Results of this analysis were wide-ranging as participants spoke to how a coaching change resulted in emotional, academic, goal, leadership, negative, positive, and culture / subculture ramifications. From this new knowledge base, researchers can better understand the lived experiences and social processes within sport (Marx, Huffman, \& Doyle, 2008) as well as aid practitioners in the development of protocols to assist athletes during this time of transition.

The findings from the higher order theme of academics helps to add to the literature base for researchers studying this traditional construct. In particular, both foundational and more contemporary works have questioned the educational attainment student-athletes experience, especially when examined through the lens of revenue producing sports (Adler \& Adler, 1985, 1991; Fountain \& Finley, 2009; Wolniak, Pierson, \& Pascarella, 2001). In the current study, not only did the clear majority of athletes $(n=43,91 \%)$ view their academic responsibilities as a priority, 19 athletes (40\%) spoke directly to how the role of academics was increased with 
the head coaching change. Although this finding may appear to contradict previous literature, it is also important to note that this study did incorporate other variables assessing academics such as: sex of the participants, type of sport played, or actual educational attainment achieved. Impression management techniques might have also influenced these findings, with the student-athletes potentially relaying what they thought we wanted to hear or information that would cast them in a more positive light. Furthermore, other studies — using both quantitative and qualitative methodologies - have found NCAA athletes are keenly aware of their academic responsibilities and receive an education experience equal to their nonathlete classmates (Paule \& Gilson, 2010; Potuto \& O'Hanlon, 2007). Thus, the present work serves as a reminder for researchers to continue work in this important area.

Examining results from a psychological lens, it is clear that the concepts of leadership and goals are vital during this important time of transition for athletes. Specifically, participants' answers highlight that new head coaches were generally aware of the importance of goal setting and incorporated many tenets advocated by Gould (2010) when goal setting with a team. However, it is also evident that new head coaches need to foster improved leadership strategies among athletes, as this higher order theme was largely absent from participants' responses. The experiences noted under this theme offer a successful template for new head coaches to follow and cultivate with their athletes. While each was at a different point in their athletic career, these two athletes both mentioned that strong team leaders were necessary to enhance the perceived stability of the team. Thus, new head coaches who prioritize getting to know their athletes and delegating leadership responsibilities to longer tenured athletes the team already trusts can avert some of the negative team unity and satisfaction perceptions experienced by athletes.

Finally, the remaining higher order themes of emotional, negative, positive, and culture / subculture effects help to paint a more complete picture of athletes while undergoing a head coaching change. As one might expect, athletes' reactions to a coaching change varied with some reporting positive benefits, others negative effects, and still other conflicted. In addition, because a change in coach can also include a culture shift, a network of support for the higher order themes identified in this paper should be established to help athletes cope with potentially dramatic shifts both in an out of sport (Aghazadeh \& Kyei, 2009; Hersch, 2012). For instance, a volleyball player worked to maintain a level of consistency among her teammates by continuing the policy of holding weekly team meetings during the coaching transition. A track and field athlete reported turning to his father for guidance during this difficult time, and partially because of his father's encouragement, this athlete chose to remain enrolled at his university even though the coaching change occurred midseason. While these stories represent adaptive behaviors, individuals should not leave this possibility to chance; therefore, a constant open line of communication should ideally already be in place so that administrators can provide the level of social support needed.

Noted limitations within the present work center around the sample interviewed and breadth of topics covered. Specifically, all participants competed at the Division I level in their respected sport. While methodological principles were employed to achieve the greatest representation of participants by sex, sport, and geographical location, this study did not focus on athletes who compete at different NCAA division levels where a coach may have additional responsibilities in 
student-athletes' lives (e.g., professor). Furthermore, because research concerning the social-psychological effects of a head coaching change is absent from the literature, this study served as an important first step in understanding this event; and thus, a decision was made to focus on breadth — as compared with depth—during interviews. Ideally future research exploring this topic would benefit from utilizing a developmental approach after athletes experience a head coaching change. This methodology would have the potential to produce significant findings showing how athletes' perceptions / experiences evolved over time. In addition, it would be interesting to quantify changes in athletes' perceptions (i.e., if athletes felt the program became stronger or weaker, if their confidence increased or decreased) depending on how they previously viewed their athletic program after a head coaching change occurred.

In conclusion, a significant percentage of athletes' collegiate experiences are invested in practicing and competing for their team (NCAA, 2012). Therefore, when a coaching change is precipitated, it is important to offer athletes an opportunity to share their feelings as well as listen to their concerns as a means to help ease the transition, especially once the new coaching staff is welcomed. While there may always be a period of uncomfortableness during this time, understanding the perspective of athletes from a social-psychological perspective can create a culture that becomes as invaluable as winning.

\section{References}

2012-13 FBS head coaching changes. (2012, December 27). Retrieved January 1, 2013, from http://espn.go.com/college-football/story/_/id/8536583/football-bowl-subdivisionhead-coaching-changes

Adler, P., \& Adler, P.A. (1985). From idealism to pragmatic detachment: The academic performance of college athletes. Sociology of Education, 58, 241-250. doi:10.2307/2112226

Adler, P., \& Adler, P.A. (1991). Backboards and blackboards: College athletes and role engulfment. New York: Columbia University Press.

Aghazadeh, S., \& Kyei, K. (2009). A quantitative assessment of factors affecting college sports' team unity. College Student Journal, 43, 294-302.

Becker, A.J. (2012). Collegiate basketball players' experiences of being coached during a turnaround season. The Sport Psychologist, 26, 43-61.

Berg, B.L. (2004). Qualitative research methods for the social sciences (5th ed.). New York: Pearson.

Beyer, J.M., \& Hannah, D.R. (2000). The cultural significance of athletics in U.S. higher education. Journal of Sport Management, 14, 105-132.

Bucci, J., Bloom, G.A., Loughead, T.M., \& Caron, J.G. (2012). Ice hockey coaches' perceptions of athlete leadership. Journal of Applied Sport Psychology, 24, 243-259. doi:10 $.1080 / 10413200.2011 .636416$

Burton, D., \& Weiss, C. (2008). The fundamental goal concept: The path to process and performance success. In T. Horn (Ed.), Advances in sport psychology (3rd ed., pp. 339-376). Champaign, IL: Human Kinetics.

Carlson, R. (1988). The socialization of elite tennis players in Sweden: An analysis of the players' backgrounds and development. Sociology of Sport Journal, 5, 241-256.

Chan, D.K., Lonsdale, C.C., \& Fung, H.H. (2012). Influences of coaches, parents, and peers on the motivational patterns of child and adolescent athletes. Scandinavian Journal of Medicine \& Science in Sports, 22, 558-568. PubMed doi:10.1111/j.16000838.2010.01277.x 
Clement, D., \& Shannon, V.R. (2011). Injured athletes' perceptions about social support. Journal of Sport Rehabilitation, 20, 457-470. PubMed

Fountain, J.J., \& Finley, P.S. (2009). Academic majors of upperclassmen football players in the Atlantic Coast Conference: An analysis of academic clustering comparing white and minority players. Journal of Issues in Intercollegiate Athletics, 2, 1-13.

Giacobbi, P., Jr., Whitney, J., Roper, E., \& Butryn, T. (2002). College coaches' views about the development of successful athletes: A descriptive exploratory investigation. Journal of Sport Behavior, 25, 164-181.

Goose, M., \& Winter, S. (2012). The coach's impact on long distance runners' training and competition motivation. International Journal of Sports Science \& Coaching, 7, 383-399. doi:10.1260/1747-9541.7.2.383

Gould, D. (2010). Goal setting for peak performance. In J.M. Williams (Ed.), Applied sport psychology: Personal growth to peak performance (6th ed., pp. 201-220). Boston, MA: McGraw Hill.

Grajfoner, D. (2009). Managing change: Role of coaching psychology in gender transition. The Coaching Psychologist, 5, 69-75.

Gyllensten, K., Palmer, S., Nilsson, E., Regnér, A., \& Frodi, A. (2010). Experiences of cognitive coaching: A qualitative study. International Coaching Psychology Review, 5, 98-108.

Hanin, Y. (2007). Coaching experience, playing experience and coaching tenure: A commentary. International Journal of Sports Science \& Coaching, 2, 129-131.

Hardman, A., Jones, C., \& Jones, R. (2010). Sports coaching, virtue ethics and emulation. Physical Education and Sport Pedagogy, 15, 345-359. doi:10.1080/17408980903535784

Hardy, C.J., \& Crace, R.K. (1990). Dealing with injury. Sport Psychology Training Bulletin, $1,1-8$.

Hersch, P.L. (2012). Does the NCAA Coaching Carousel Hamper the Professional Prospects of College Football Recruits? Journal of Sports Economics, 13, 20-33. doi:10.1177/1527002510391806

Horn, T.S. (2008). Coaching effectiveness in the sport domain. In T.S. Horn (Ed.), Advances in sport psychology (3rd ed., pp. 239-267). Champaign, IL: Human Kinetics.

Jackson, B., Dimmock, J.A., Gucciardi, D.F., \& Grove, J. (2011). Personality traits and relationship perceptions in coach-athlete dyads: Do opposites really attract? Psychology of Sport and Exercise, 12, 222-230. doi:10.1016/j.psychsport.2010.11.005

Judge, L.W., Bellar, D., Blom, L.C., Don, L., Harris, B., Turk, M., . . Johnson, J. (2012). Perceived social support from strength and conditioning coaching among injured student athletes. Journal of Strength and Conditioning Research, 26, 1154-1161. PubMed doi:10.1519/JSC.0b013e31822e008b

Kamphoff, C.S., Armentrout, S.M., \& Driska, A. (2010). The token female: Women's experiences as Division I collegiate head coaches of men's teams. Journal of Intercollegiate Sport, 3, 297-315.

Kristiansen, E.E., Tomten, S.E., Hanstad, D.V., \& Roberts, G.C. (2012). Coaching communication issues with elite female athletes: Two Norwegian case studies. Scandinavian Journal of Medicine \& Science in Sports, 22, 156-167. PubMed doi:10.1111/j.16000838.2010.01157.x

List of current NCAA Division I women's basketball coaches. (n.d.). Retrieved January 1, 2013 from http://en.wikipedia.org/wiki/List_of_current_NCAA_Division_I_ women\%27s_basketball_coaches

MacNamara, Á., \& Collins, D. (2010). The role of psychological characteristics in managing the transition to university. Psychology of Sport and Exercise, 11, 353-362. doi:10.1016/j.psychsport.2010.04.003

Marx, J., Huffman, S., \& Doyle, A. (2008). The student-athlete model and the socialization of intercollegiate athletes. Athletic Insight: The Online Journal of Sport Psychology. Retrieved January 1, 2013, from http://www.athleticinsight.com/Vol10Iss1/StudentAthleteModel.htm 
NCAA. (2012, August 1). 2012-13 NCAA Division I manual: Operating manual. Retrieved January 1, 2013, from http://www.ncaapublications.com/productdownloads/D113.pdf

Paquette, K.J., \& Sullivan, P. (2012). Canadian curling coaches' use of psychological skills training. The Sport Psychologist, 26, 29-42.

Pate, J.R., Stokowski, S.E., \& Hardin, R. (2011). Third time's a charm: The case of Tennessee's four junior football players who endured three different head coaches in three seasons. Journal of Issues in Intercollegiate Athletics, 4, 354-369.

Patton, M.Q. (2002). Qualitative research and evaluation methods (3rd ed.). Thousand Oaks, CA: Sage Publications.

Paule, A.L., \& Gilson, T.A. (2010). Current collegiate experiences of big-time, non-revenue, NCAA athletics. Journal of Intercollegiate Sport, 3, 333-347.

Potuto, J.R., \& O'Hanlon, J. (2007). National study of student-athletes regarding their experiences as college students. College Student Journal, 41, 947-966.

Rhind, D.A., Jowett, S.S., \& Yang, S.X. (2012). A comparison of athletes' perceptions of the coach-athlete relationship in team and individual sports. Journal of Sport Behavior, $35,433-452$.

Sievert, J.P. (2011). Coaching changes and NCAA transfer rules: Is the current system leaving athletes abandoned? Willamette Sports Law Journal, 9, 47-80.

Silverman, D. (2001). Interpreting qualitative data (2nd ed.). London: Sage.

Soebbing, B.P., \& Washington, M. (2011). Leadership succession and organizational performance: Football coaches and organizational issues. Journal of Sport Management, 25, 550-561.

Tawse, H., Bloom, G.A., Sabiston, C.M., \& Reid, G. (2012). The role of coaches of wheelchair rugby in the development of athletes with a spinal cord injury. Qualitative Research in Sport. Exercise \& Health, 4, 206-225. doi:10.1080/2159676X.2012.685104

Tharp, R.G., \& Gallimore, R. (1976). What a coach can teach a teacher. Psychology Today, 9, 75-78.

Vallée, C.N., \& Bloom, G.A. (2005). Building a successful university program: Key and common elements of expert coaches. Journal of Applied Sport Psychology, 17, 179-196. doi:10.1080/10413200591010021

Wolniak, G.C., Pierson, C.T., \& Pascarella, E.T. (2001). Effects of intercollegiate athletic participation on male orientations toward learning. Journal of College Student Development, 42, 604-624.

Zaccaro, S.J., Rittman, A.L., \& Marks, M.A. (2001). Team leadership. The Leadership Quarterly, 12, 451-483. doi:10.1016/S1048-9843(01)00093-5 